\title{
Editorial
}

\section{The roles of managers in addressing Sustainable Development Goals and addressing the burden of chronic disease}

One of my colleagues, [1] a student from Bhutan at the Naresuan University College of Health System Management (NUCHSM) Thailand recently presented her research findings about childhood obesity in Bhutan that included a finding that health managers had a responsibility to ensure that services addressed this significant health issue. That their staff, policies and resources available were addressing this issue and that their local communities were aware and well informed and engaged in addressing this worldwide challenge. This research is yet to be published but this connection with the management role and responsibility resonated with me as an important finding and recommendation.

It did so both in terms of management accountability but also in broader concepts of what our expectations of the modern managers role is and perhaps where it should be. It also reminded me about where Australia stands in the management of chronic diseases and in utilising the UN Sustainable Development Goals (SDGs) initiative. Finally, I ask is this a reasonable approach for managers to become more involved in addressing the negative health impacts implicit in many of our communities arising from socio-economic determinants of health (SOECD)?

All too often we see the leadership of managers focussed on organisations and pre and centrally determined range of services that are consistently delivered across Australia. All too often these services might have a 'hub and spoke' type level of delivery. The further away from the hub the increased propensity for poorer access through both considerations of equity of access of marginalised groups, the tyranny of distance, transport access and an inadequate professional health workforce.

Developing countries know these challenges well and are shaping their research, programs and collaborative engagement across sectors to address the UN SDG challenge. [2] In Australia, similar challenges exit, particularly in rural and remote and regional centres. Might we see potential in engaging managers together with researchers, providers, health professionals and communities in specific community-based projects?

The 17 Sustainable Development Goals (SDGs) are said to

'form a roadmap for global development efforts to 2030 and beyond. The Sustainable Development Goals, together with the Addis Ababa Action Agenda on Financing for Development (a global plan for financing the Goals) form the 2030 Agenda for Sustainable Development. There are 169 targets within the Sustainable Development Goals and each goal has a set of indicators to help measure progress'. [3]

The main SDG that impacts on health and wellbeing is SDG3 that is meant to 'ensure healthy lives and promote well-being for all at all ages.' Commonwealth responsibility for this SDG rests with the Department of Health. The recent Report on the Implementation of the Sustainable Development Goals 2018, United Nations High-Level Political Forum on Sustainable Development 2018 for the Australian Government is at 
https://www.sdgdata.gov.au/about/voluntary -national-review

'Many Australians are familiar with the concept of sustainable development but may not be aware of the SDGs and their universal nature. Some national and local institutions and organisations have adopted the SDG framework and integrated them into their policies and budgets'. [3, P.12] All SDGs are in some respects inter-connected and have some broader implications for health systems and the health of local communities. the SDGs provide a framework through 'which governments, businesses, organisations and individuals can conceive of a problem or objective and devise action to drive progress'. [3,p.15] According to the Report

'a lot of organisations are seeing the power of the SDGs as a holistic framework and approach to environmental health, human wellbeing, economic sustainability and long-term profitability. The SDGs provide a tool for organisations to identify and mitigate risk and opportunity, including in areas they might previously not have seen as linked to core business'. [3,p.18]

'For some, the SDGs present a new lens through which organisations can approach their strategic planning, projects, programs and a recognisable global platform to guide collaboration with others.' [3,p17]

Ensuring healthy lives and promoting wellbeing at all ages is SDG 3 and is the specific but not conclusive health service SDG. The Australian National SDG review indicates there is more to be done:

'While there are positive signs and progress on many fronts, it is clear that Australia is not healthy in every way, and some patterns and trends give cause for concern. Chronic diseases ... are becoming increasingly common in Australia due to a population that is increasing and ageing, as well as to social and lifestyle changes. ... Presenting a broad picture of health status can mask the fact that some groups in our community are not faring as well, including people living in rural and remote areas, the lowest socioeconomic groups, Indigenous Australians and people living with disability.' Australian Institute of Health and Welfare, Australia's Health 2016 [3 p.32]

It seems to me that there is a lot of good material in these Reports that suggests there is much to done. A lot of activity seems to be occurring at national state and organisational levels in public and private sectors across Australia. It brings me back to my colleagues view that managers have a responsibility in addressing the chronic burden of disease based SOECD and through the attainment of SDG 3. Particularly at the local level how might managers be more effective in progressing local achievement.

In the context of Thailand they are working at the local District Health Service Level to strengthen management capacity at that level, to establish a health district learning network between DHS staff and management together with the health systems academic/research faculty. They are taking participatory, collaborative action-based approaches. They want to achieve a common vision and agreed strategic approaches, capacity building to ensure a well trained health workforce, through collaborative action research, shared learning all to achieve better PHC focussed on progress in achieving SDG3. [2]

The Australian 2018 Review of SDGs clearly demonstrates the potential for action at local organisational and community levels to utilise the SDGs for improved performance. Are our health managers up to the challenge?

\section{DS Briggs}

\section{Editor}




\section{References}

1. Chimi Wangmo 2018 An Exploratory Study on the Roles of Bhutanese Primary Healthcare Managers in Responding to Childhood Obesity, Master of Science in Health Systems Management Thesis, College of Health Systems Management, Naresuan University, Phitsanulok, Thailand.

2. Phudit Tejativaddhana, David Briggs, Orapin Singhadej, Reggie Hinoguin, 92018) 'Developing primary healthcare in Thailand: Innovation in the use of socio-economic determinants, Sustainable Development Goals and the district health strategy'. Public Administration and Policy, https://doi.org/10.1108/PAP-06-2018-005. Permanent link to this document: https://doi.org/10.1108/PAP-06-2018-005.

3. Report on the Implementation of the Sustainable Development Goals 2018 United Nations High-Level Political Forum on Sustainable Development 2018 Australian Government. https://dfat.gov.au/aid/topics/developmentissues/2030-agenda/Pages/sustainabledevelopment-goals.aspx. 